\title{
Longitudinal bulk acoustic mass sensor
}

\author{
Hales, Jan Harry; Teva, Jordi; Boisen, Anja; Davis, Zachary James
}

\section{Published in:}

Applied Physics Letters

Link to article, DOI:

$10.1063 / 1.3168519$

Publication date:

2009

Document Version

Publisher's PDF, also known as Version of record

Link back to DTU Orbit

Citation (APA):

Hales, J. H., Teva, J., Boisen, A., \& Davis, Z. J. (2009). Longitudinal bulk acoustic mass sensor. Applied Physics Letters, 95(3), 033506. https://doi.org/10.1063/1.3168519

\section{General rights}

Copyright and moral rights for the publications made accessible in the public portal are retained by the authors and/or other copyright owners and it is a condition of accessing publications that users recognise and abide by the legal requirements associated with these rights.

- Users may download and print one copy of any publication from the public portal for the purpose of private study or research.

- You may not further distribute the material or use it for any profit-making activity or commercial gain

- You may freely distribute the URL identifying the publication in the public portal

If you believe that this document breaches copyright please contact us providing details, and we will remove access to the work immediately and investigate your claim. 


\title{
Longitudinal bulk acoustic mass sensor
}

\author{
J. H. Hales, ${ }^{\text {a) }}$ J. Teva, A. Boisen, and Z. J. Davis \\ Department of Micro and Nanotechnology-DTU Nanotech, Technical University of Denmark, DTU Bldg. \\ 345 East, DK-2800 Kongens Lyngby, Denmark
}

(Received 12 February 2009; accepted 1 June 2009; published online 21 July 2009)

\begin{abstract}
A polycrystalline silicon longitudinal bulk acoustic cantilever is fabricated and operated in air at 51 MHz. A mass sensitivity of $100 \mathrm{~Hz} / \mathrm{fg}\left(1 \mathrm{fg}=10^{-15} \mathrm{~g}\right)$ is obtained from the preliminary experiments where a minute mass is deposited on the device by means of focused ion beam. The total noise in the currently applied measurement system allows for a minimum detectable mass of $0.5 \mathrm{fg}$ in air. () 2009 American Institute of Physics. [DOI: 10.1063/1.3168519]
\end{abstract}

The presented research aims at developing high- $Q$ silicon based devices for ultrasensitive mass detection in viscous fluids-initially in air and ultimately in liquids. Especially the latter is a paramount property to achieve the final goal of fulfilling the demand for robust real time portable diagnostic applications. We will present a mass sensor based on a longitudinal bulk acoustic cantilever with a $Q$ factor of 3100 in air. Preliminary results yield a mass sensitivity of $100 \mathrm{~Hz} / \mathrm{fg}\left(1 \mathrm{fg}=10^{-15} \mathrm{~g}\right)$ and a minimum detectable mass of $0.5 \mathrm{fg}$, which makes this a promising technology especially since these measurements have been performed in air at ambient conditions. This initial mass sensitivity characterization has been conducted by depositing a platinum compound by means of focused ion beam (FIB) equipment. The novelty of this research is comprised by the achieved high mass sensitivity and $Q$ factor augmented by the simple microelectromechanical system fabrication, which is complementary metal-oxide-semiconductor compatible.

So far the highest mass sensitivity, regarding mechanical resonators, has been obtained by flexural type. ${ }^{1,2}$ However when turning to bio/chemical detection in higher viscous regime than vacuum, these flexural devices experience severe challenges caused by the increased hydrodynamic damping. Thus bulk acoustic technology becomes interesting especially due to the reported high $Q$ factors $\left(\sim 10^{4}-10^{5}\right)$ in air. ${ }^{3,4}$ Previous work on bulk acoustic mode resonators are primarily focused on frequency reference applications aimed at the consumer electronics market. ${ }^{5,6}$ A few groups, however, have demonstrated mass bulk acoustic mass sensing, obtaining $215 \mathrm{~Hz} / \mathrm{pg}$ in air $^{7}$ and $3.5 \mathrm{~Hz} / \mathrm{ng}$ in vacuum. ${ }^{4}$ Another type is the thin-film bulk acoustic resonators (FBARs), which have been utilized as mass sensors ${ }^{8,9}$ with point mass sensitivity in the low femtograms. The drawback of FBARs are their large footprint, compared to the presented device, thus limiting the possibility for sensor arrays. Additionally, the use of piezoelectric material such as $\mathrm{ZnO}$ and AlN increases the fabrication complexity.

The device is operated in a longitudinal extensional mode, as shown in Fig. 1(a), where the two cantilevers constituting the resonator are moving along the length in antiphase motion. This mode is actuated electrostatically and the resulting resonance frequency is detected by capacitive readout between the two electrodes and the resonator, as

${ }^{a)}$ Electronic mail: jan.hales@gmail.com. shown in Fig. 1(b). The time varying motional output current $i_{\text {out }}$ measured at the sense electrode is given by

$$
i_{\text {out }}=V_{\mathrm{dc}} \frac{d C_{0}}{d l} \frac{d l}{d t},
$$

where $V_{\mathrm{dc}}$ is the applied dc voltage, $C_{0}$ is the static capacitance between the resonator, and the electrodes and $d l$ is the longitudinal displacement.

The mass sensitivity of the sensor is given by the linear relation in Eq. (2) for $\Delta m \ll m_{\text {eff: }}$ :

$$
\frac{\Delta m}{\Delta f}=\frac{2 m_{\mathrm{eff}}}{f_{0}},
$$

where $f_{0}$ is the initial resonance frequency, $\Delta m$ is the added mass, $\Delta f$ is the change in frequency, and $m_{\text {eff }}$ is the effective mass of the resonator. The latter depends on the mode shape but, in this longitudinal extensional case, it can be estimated as one-half of the actual mass of the resonator. ${ }^{10}$ The analytical expression for the resonance frequency of an ideal clamped-free beam operated in bulk acoustic mode is given by ${ }^{10}$

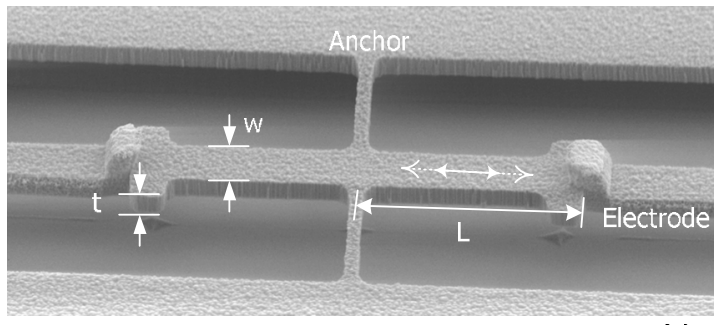

(a)

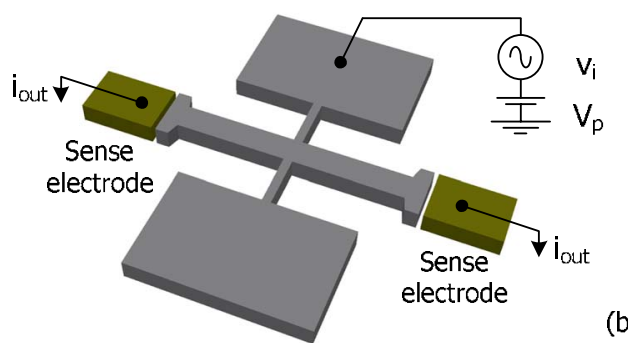

(b)

FIG. 1. (Color online) Picture (a) shows a SEM image of the resonator where the mode of vibration is indicated along with the length $L=30 \mu \mathrm{m}$, width $w=2.5 \mu \mathrm{m}$, and a thickness of $t=2.3 \mu \mathrm{m}$. (b) shows a schematic of the applied one-port actuation and readout scheme, where the output electrodes $\left(i_{\text {out }}\right)$ are combined and connected to the network analyzer input. 


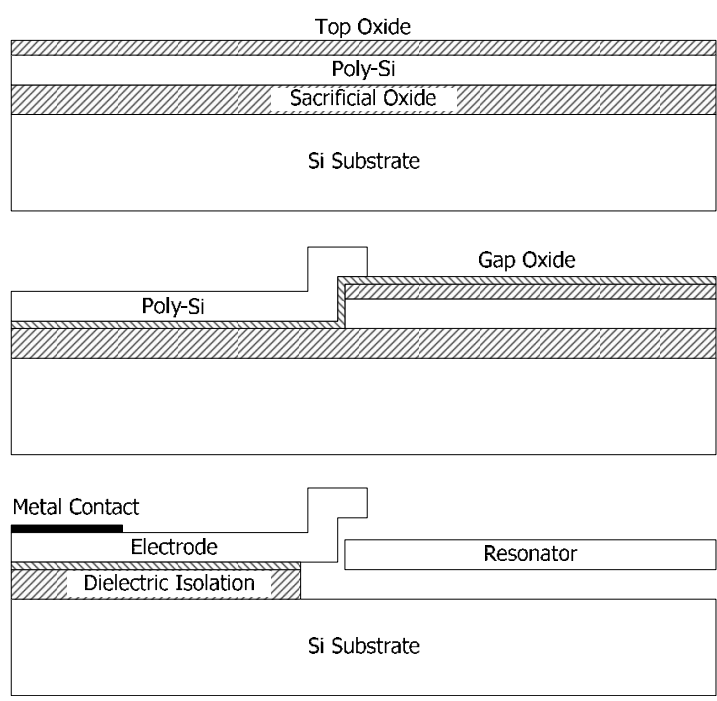

FIG. 2. Outline of the fabrication process given in cross-sectional views. Initially the polycrystalline $\mathrm{Si}$ and hard mask top oxide is deposited through a low pressure chemical vapor deposition process on top of the $5 \mu \mathrm{m}$ thick PECVD oxide. Next the resonator structure is defined followed by the deposition of first the gap oxide and subsequently the second layer of polycrystalline Si. The latter is patterned to form the electrodes. Finally the metal contacts are created and the resonator is released in HF.

$$
f_{0}=\frac{1}{4 L} \sqrt{\frac{E}{\rho}},
$$

where $E$ and $\rho$ are the Young's modulus and density, respectively, of the resonator material and $L$ is the length of a single cantilever measured from the middle anchoring, as shown in Fig. 1(a). As also seen from Fig. 1(a), an alteration of the end part of the cantilever from the ideal beam case is implemented. This ensures good electrode-resonator overlap despite a decrease in line width during fabrication. The altered geometry results in the following analytical expression for the resonance frequency:

$$
f_{0}=\frac{1}{4 L} \sqrt{\frac{1}{1+\frac{2}{w_{e} L_{e}}} \frac{E}{\rho}},
$$

where $w_{e}$ and $L_{e}$ are the width and length of the end part exceeding the width of the beam, respectively.

A three mask fabrication scheme with five major steps, outlined in Fig. 2 is applied to realize the resonator. The scanning electron microscope (SEM) image in Fig. 1(a) shows the resulting device where the resonator and the electrodes are defined by standard UV lithography using in situ boron doped polycrystalline silicon as resonator structural material. The underlying $5 \mu \mathrm{m}$ thick plasma enhanced chemical vapor deposited (PECVD) oxide serves both to minimize the contact capacitance to the substrate and as a sacrificial layer. The thick oxide increases the yield of the subsequent device release in hydrofluoric acid (HF) by minimizing the possibility of stiction between the substrate and the suspended device.

Initial characterization of the device is shown in Fig. 3 where the effect of electrostatic spring softening, as expected, is seen to decrease the resonance frequency linearly with the applied dc voltage squared. The unperturbed inherent resonance frequency is found to be $51.0032 \mathrm{MHz}$ by extrapolating the linear fit to zero applied dc bias voltage.

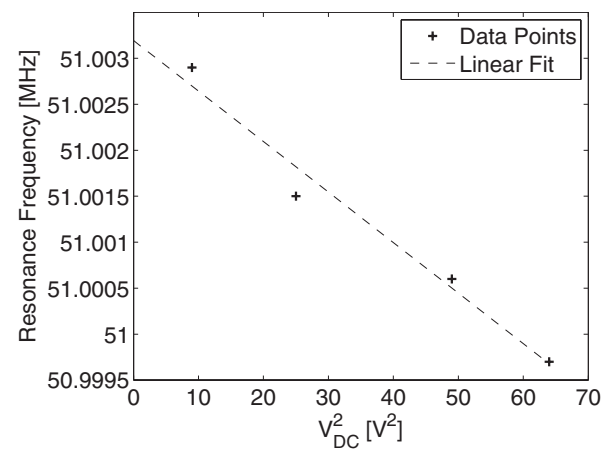

FIG. 3. Effect of electrostatic spring softening is seen. The fundamental resonance frequency of $51.0032 \mathrm{MHz}$ is found from extrapolating the shown linear fit to $V_{\mathrm{dc}}=0 \mathrm{~V}$.

From finite element method analysis this frequency corresponds to a Young's modulus of $160 \mathrm{GPa}$, which is in good agreement with similar polycrystalline silicon films previously reported. ${ }^{11}$ From the resonance response a $Q$ factor of 3100 is found, which is considered good for the specific device, but indicates that there is still room for improvement compared to similar (monocrystalline $\mathrm{Si}$ ) devices operated in vacuum. ${ }^{12}$

To evaluate the mass sensitivity, the device is first measured in air, then a small mass of a platinum compound is deposited on the resonator structure, as seen in Fig. 4. This is achieved through ion beam assisted deposition from a organometallic precursor being $\mathrm{C}_{5} \mathrm{H}_{5} \mathrm{Pt}\left(\mathrm{CH}_{3}\right)_{3}$ for the case of $\mathrm{Pt}$ deposition. The resulting compound consist of $\mathrm{C}, \mathrm{O}, \mathrm{Pt}$, and Ga $(45 \%-55 \%, 5 \%, 40 \%-50 \%$, and 5\%-7\%, respectively), where composition variation depends on the purity of the source and vacuum environment of the FIB system. ${ }^{13}$ Finally, after FIB deposition the device is again measured in air.

From SEM inspection, the dimension of the Pt deposition is obtained, resulting in an estimation of the added mass to be around $484 \pm 91 \mathrm{fg}$, where the error is based on the afore shown composition variation. Inevitably further characterization of the actual composition is needed to precisely determine the added mass. ${ }^{13,14}$

The resonance signal before and after the mass deposition is shown in Fig. 5. Rewriting the sensitivity expression in Eq. (2) and using that the decrease in frequency is $47 \mathrm{kHz}$ from the initial resonance frequency. A mass change of 554 $\mathrm{fg}$ is attained. This mass change is found to be in good agreement with the estimated added mass of $484 \pm 91 \mathrm{fg}$.

From the expression in Eq. (2) the previous stated sensitivity of $100 \mathrm{~Hz} / \mathrm{fg}$ is obtained from an effective mass calculated based on SEM images and a density of polycrystal-
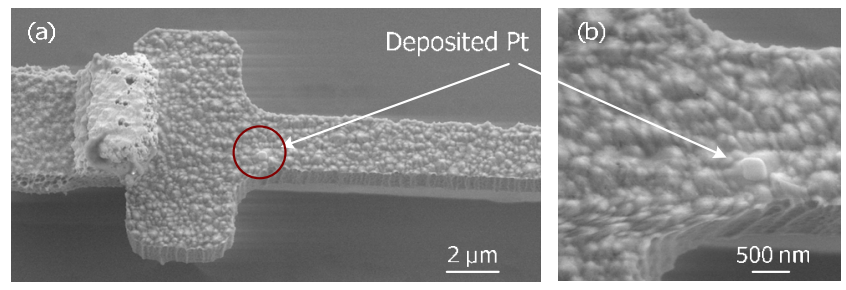

FIG. 4. (Color online) SEM images of mass loaded resonator where the $\mathrm{Pt}$ compound has been deposited. The volume of the Pt deposit is estimated as a square of side length $370 \mathrm{~nm}$ with a thickness of $340 \mathrm{~nm}$. This yields an estimated mass loading of $484 \pm 91 \mathrm{fg}$. 

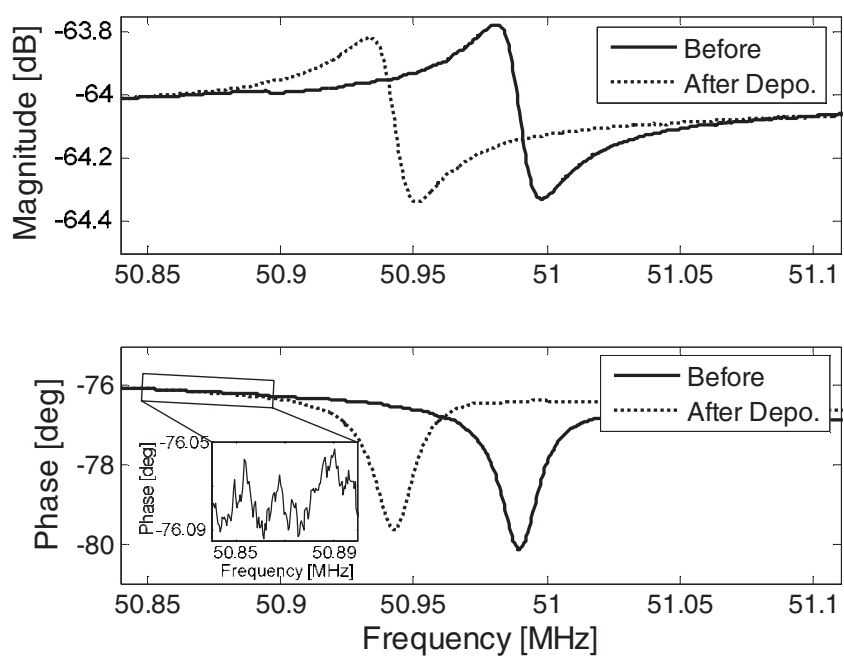

FIG. 5. Magnitude and phase of the resonance signal measured in air before and after the deposition of the Pt compound. The inset shows the phase noise. The device is driven at an ac voltage of $650 \mathrm{mV}$ and a dc voltage of $8 \mathrm{~V}$. The change in frequency corresponds to a calculated mass change of $554 \mathrm{fg}$.

line silicon of $2300 \mathrm{~kg} / \mathrm{m}^{3}$ along with the resonance frequency $f_{0}=51 \mathrm{MHz}$. By looking at the phase noise of the entire system $d \Theta_{\text {noise, }}$, which amounts to $0.01^{\circ}$ and the slope of the phase signal at the resonance frequency $d \Theta_{n} / d f_{n}(-2$ $\times 10^{-4}$ degrees $/ \mathrm{Hz}$ ) the resulting experimental minimum detectable mass is found from Eqs. (5) and (2) to be $0.5 \mathrm{fg}$,

$$
d f_{\min }=\frac{d \Theta_{\text {noise }}}{d \Theta_{n} / d f_{n}} .
$$

This value shows that there is room for improvement since the ultimate mass detection, based purely on thermomechanical noise is 3 ag. ${ }^{15}$

The long term frequency stability will have to be further investigated, as this will directly impact the sensitivity. Results from similar devices from the same batch have shown a frequency stability, on the time scales corresponding to the described characterization experiment, indicating an up to factor 10 increase in minimum detectable mass.

In conclusion, a longitudinal bulk acoustic mass sensor with a sensitivity of $100 \mathrm{~Hz} / \mathrm{fg}$ in air have been presented. To our knowledge this constitutes an unprecedented demonstration of point mass sensitivity in air, for bulk acoustic resonators. Through the simple characterization by means for FIB assisted Pt deposition, it has been shown that these type of resonators have great potential as mass sensors in air due to the high $Q$ factor and in-plane motion.

${ }^{1}$ M. Li, H. X. Tang, and M. L. Roukes, Nat. Nanotechnol. 2, 114 (2007).

${ }^{2}$ B. Ilic, H. G. Craighead, S. Krylov, W. Senaratne, C. Ober, and P. Neuzil, J. Appl. Phys. 95, 3694 (2004).

${ }^{3} \mathrm{H}$. Johari and F. Ayazi, Proceedings of the IEEE International SOI Conference, 2007 (unpublished), pp. 153-154.

${ }^{4}$ J. E. Y. Lee, B. Bahreyni, Y. Zhu, and A. A. Seshia, Appl. Phys. Lett. 91, 234103 (2007).

${ }^{5}$ J. Clark, W.-T. Hsu, M. Abdelmoneum, and C.-C. Nguyen, J. Microelectromech. Syst. 14, 1298 (2005).

${ }^{6}$ L. Khine, M. Palaniapan, and W. K. Wong, Proceedings of Transducers and Eurosensors, 2007 (unpublished), pp. 2445-2448.

${ }^{7}$ H. Zhili, R. Abdolvand, and F. Ayazi, 19th IEEE International Conference on Micro Electro Mechanical Systems, 2006 (unpublished), pp. 598-601.

${ }^{8}$ H. Campanella, A. Uranga, A. Romano-Rodriguez, J. Montserrat, G. Abadal, N. Barniol, and J. Esteve, Sens. Actuators, A 142, 322 (2008).

${ }^{9}$ H. Zhang, M. S. Marma, E. S. Kim, C. E. McKenna, and M. E. Thompson, J. Micromech. Microeng. 15, 1911 (2005).

${ }^{10}$ W. Weaver, Jr., S. P. Timoshenko, and D. H. Young, Vibration Problems in Engineering (Wiley, New York, 1990).

${ }^{11}$ D. Maier-Schneider, J. Maibach, E. Obermeier, and D. Schneider, J. Micromech. Microeng. 5, 121 (1995).

${ }^{12}$ T. Mattila, J. Kiihamäki, T. Lamminmäki, O. Jaakkola, P. Rantakari, A. Oja, H. Seppä, H. Kattelus, and I. Tittonen, Sens. Actuators, A 101, 1 (2002).

${ }^{13}$ R. M. Langford, T. X. Wang, and D. Ozkaya, Microelectron. Eng. 84, 784 (2007).

${ }^{14}$ A. Vila, F. Hernandez-Ramirez, J. Rodriguez, O. Casals, A. RomanoRodriguez, J. R. Morante, and M. Abid, Mater. Sci. Eng., C 26, 1063 (2006)

${ }^{15}$ K. L. Ekinci, Y. T. Yang, and M. L. Roukes, J. Appl. Phys. 95, 2682 (2004). 